\title{
Effect of Radioactive Fallout Upon the Electrical Conductivity of the Lower Atmosphere
}

\author{
Akira HuziTa \\ Department of Health Physics and Instrumentation, \\ Radiation Centre of Osaka Prefecture, Sakai, Osaka. \\ (Received February 20, 1966)
}

\begin{abstract}
The effect of radioactive fallout upon the electrical conductivity of the lower atmosphere has been studied. The records of atmospheric conductivity which were made at the Geophysical Institute of Kyoto University in the period from 1961 to 1963 were compared with the records of the observation of fallout made in the same period at the Radiation Centre of Osaka Prefecture. The radioactive fallout, which originated from the large scale nuclear test explosion of $50 \mathrm{Mega}$ ton class carried out by the U.S.S.R. at Novaya Zyemlya on October 30,1961, caused a temporary increase in atmospheric conductivity up to the value twice as high as the normal value. The increase in conductivity was caused mainly by radiations from the dry fallout accumlated on the ground surface, which was estimated to have exceeded $250 \mathrm{~m} \mu \mathrm{Ci} / \mathrm{m}^{2}$ at that time. On the other hand, radiations from the airborne nuclear debris, the concentration of which reached as high as $120 \mu \mu \mathrm{Ci} / \mathrm{m}^{3}$ at that time, were considered to have contributed little to the increase in conductivity.
\end{abstract}

\section{Introduction}

There have been some investigations on the effects of radioactive fallout on the atmospheric electricity. Harris (1955) found an effect caused by the nuclear debris originating from the Nevada nuclear test explosion in the records of the atmospheric conductivity and the potential gradient at Tucson Magnetic Observatory, Arizona. Thereby the conductivity was observed to be increased to about tenfold, and the potential gradient was observed to be decreased by a factor of six. The conductivity recovered to the normal low value according to the equation, $\lambda=\lambda_{A}+\lambda_{0} t^{-1.2}$, where $\lambda$ is conductivity, $\lambda_{A}$ is the average conductivity for 24 hour period just preceding the fallout, $\lambda_{0}$ is a constant and $t$ is the time elapsed after the explosion. The radioactivity of the fission products from ${ }^{235} \mathrm{U}$ slow neutron fission decay roughly after $t^{-1,2}$. Therefore the abnormal increase in conductivity was caused by radiations from the radioactive fallout.

Pierce $(1957,1959)$ studied the secular variation of potential gradient at Eskdalemuir, Scotland and pointed out that the observed decrease in potential gradient had been caused by both the accumulation of fallout on the ground surface and the influence of steady leakage from the atomic pile of Windscale.

Kondo $(1957,1963)$ who studied the secular variation of atmospheric electricity recent years at Kakioka, Japan, found an increase in conductivity and a decrease in potential gradient and concluded that these were caused by the accumulation of fallout on the ground 
surface.

Near the test ground, where the fallout deposition is seriously much, the atmospheric electricity varies tempotarily and strongly. Far from the test ground, however, fallout deposition is usually so little that the atmospheric electric elements are varied only a little by fallout; the effects of fallout on the atmospheric electricity is not conspicuous, because a little variation due to fallout is blanketed by larger ones due to the local conditions. It is generally recognized, however, that the secular variations due to radioactive fallout are only detected by statistical analyses of the data accumulated for a long period.

A thermonuclear test explosion of 50 Mega ton class was carried out at Novaya Zyemlya, U.S.S.R. on October 30, 1961, Several days afterwards, much nuclear debris were detected even in Japan about $6,000 \mathrm{~km}$ far apart from the test ground (Mamuro et al., 1962). Then a considerable increase in atmospheric electrical conductivity was observed in Kyoto. In Osaka, high concentration of radioactive fallout in the air and seriously much dry fallout deposition on the ground surface were observed. As Kyoto is only $40 \mathrm{~km}$ apart from Osaka, the rate of fallout deposition seems to have been almost the same in both districts. In the present investigation, has been studied the relation between the increase in conductivity and the increase in radioactive fallout.

\section{Results of Observation}

1. Variation of fallout concentration in the air and that of atmospheric electrical conductivity.

Observation of fallout concentration in the air has been carried out by the filter paper method since September 1961, when a series of nuclear test explosions was set out by the U.S.S.R. (Mamuro et al., 1961, 1962). Radioactive dusts were collected on a filter paper (Toyo Roshi No. 5A) through which air was filtered with the aid of a suction pump. Beta activities of the dust samples were measured by a G.M. counter.

Fallout concentration in the air increased up to $120 \mu \mu \mathrm{Ci} / \mathrm{m}^{3}$ on November 7,1961 . The concentration kept still high on 8th and decreased a little on 9 th, then became very low on 10th. Average natural radioactivity concentration in the air is some hundred $\mu \mu \mathrm{Ci} / \mathrm{m}^{3}$ (Kawano and Nakatani, 1958, 1963). On November 7 and 8, fallout concentration was comparable to natural radioactivity concentration. The variation of fallout concentration at that time is shown by open circles in Fig. 1.

The variation of atmospheric electrical conductivity had been observed at the Geophysical Institute of Kyoto University using a Gerdien type conductivity-meter (Chalmers, 1957; Ogawa, 1960a). In the period from 8 to 11, November, 1961, large deflections were recorded by the conductivity-meter. [Unfortunately, no data was obtained on November 7, 1961 because of instrument failure.] Not only the conductivity increased remarkably, but also the zero level of the conductivity-meter shifted largely. The conductivity increased in this period to about twice as high as the normal value. The solid circles in Fig. 1 show the variation of conductivity averaged daily.

The diurnal variations of atmospheric electrical conductivity and of potential gradient 


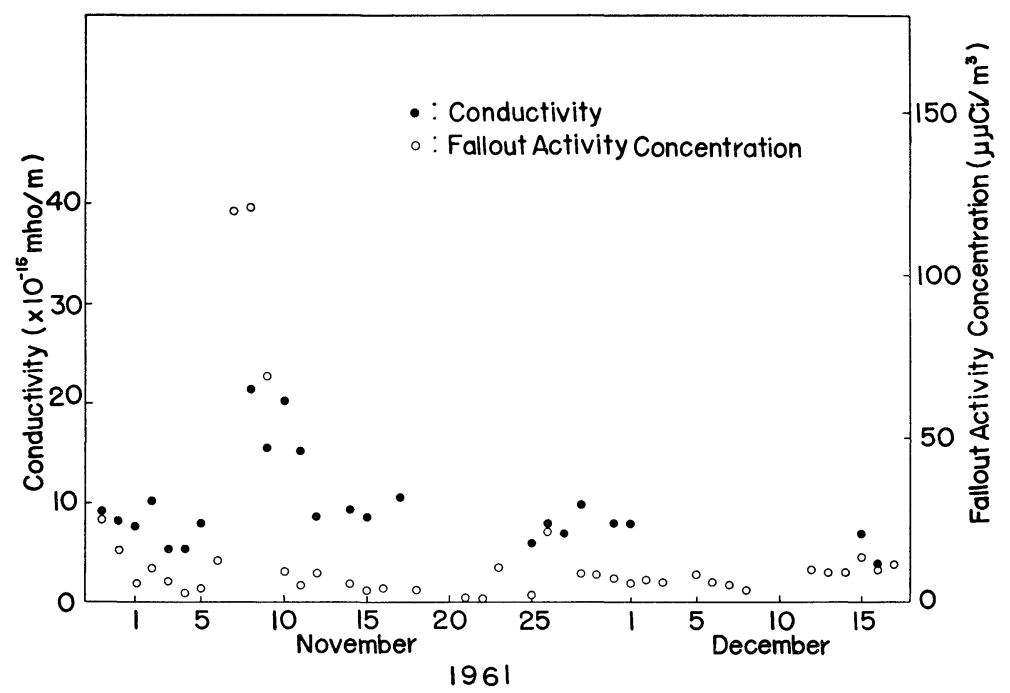

Fig. 1 Variation of atmospheric electrical conductivity and of radioactive fallout concentration in the air in November and December, 1961.

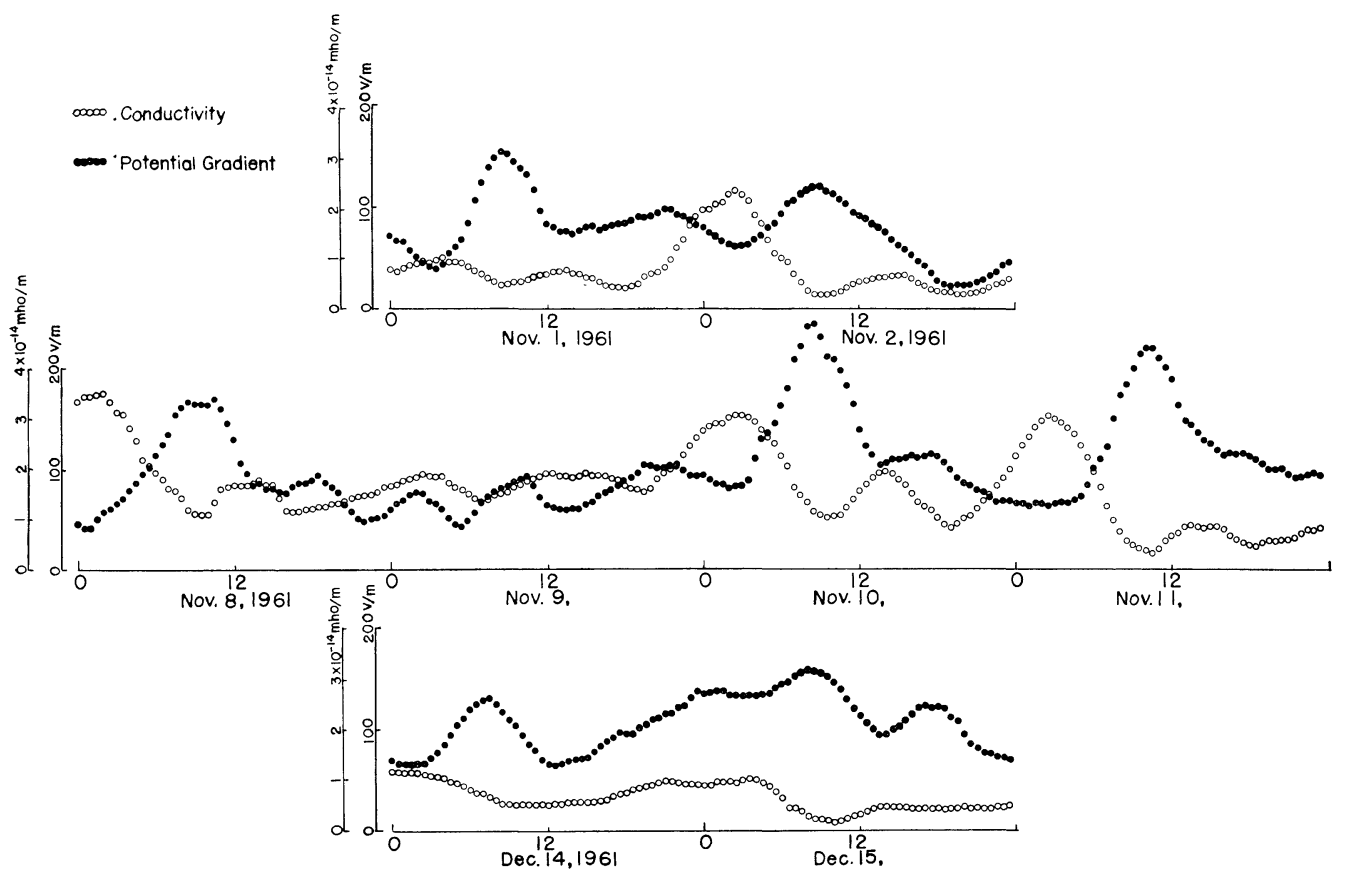

Fig. 2 Variations of atmospheric electrical conductivity and of potential gradient.

which were observed in the poriods from Novemver 8 to 11, from November 1 to 2 , and from December 14 to 15 are shown in Fig. 2 by open circles and solid circles, respectively. The measured values were read out of the recording charts every $30 \mathrm{~min}$., and the overlapping mean values for 5 hours were taken, in order to eliminate short period variations. It is realized from Fig. 2 that the mode of diurnal variation in atmospheric electricity on Novem- 


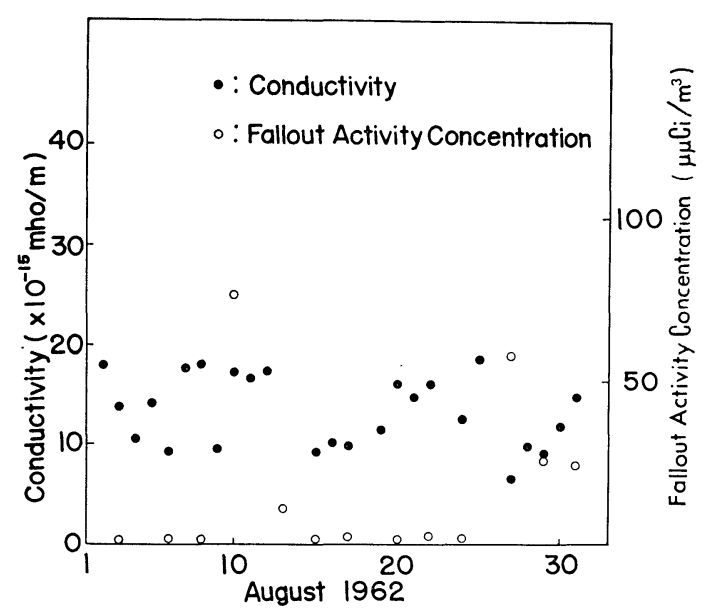

Fig. 3 Variations of atmospheric electrical conducti vity and of radioactive fallout concentration in the air in August, 1962.

filter is equipped at the entrance of the chamber which operates for a few minutes every one hour. The zero level shifted largely up to 8 divisions of the chart of 50 division full scale on November 8, 1961 and recovered gradually with time. It is experienced sometimes that the zero level shifts a little when atmospheric moisture increases, but the shifting recovers soon after it become dry. The observed shifting seemed not to have been caused by leakage of electric charge through the insulator which holds the inner electrode. The recovery curve of the zero level shift is shown by solid circles in Fig. 4. The radioactivity decay curve of the air-borne dusts collected on Novenber 7, 1961 is also shown by open circles in Fig. 4. It is noticed that the gradients of these two curves are quite similar to each other.

The activity of fission products produced by slow neutron fission of ${ }^{235} \mathrm{U}$ decays after the Hunte $r$-Ballou (1951)'s law; $A=A_{0} t^{-12}$, where $A$ is the activity, $A_{0}$ is a constant and $t$ is ber 8 and 9 was not at all different from the normal one.

On August 10 in the next year, 1962, fallout concentration in the air increased up to $76 \mu \mu \mathrm{Ci} / \mathrm{m}^{3}$ shortly after the nuclear test explosion by the U.S.A. The variation of fallout concentration in the air and that of conductivity which were observed at that time are shown in Fig. 3 by open circles and solid circles, respectively. It is noticed that conductivity was varied little by fallout at that time.

2. Zero level shift of the Gerdien conductivity-meter.

In order to find the zero level shift of the Gerdien conductivity-meter, an ion

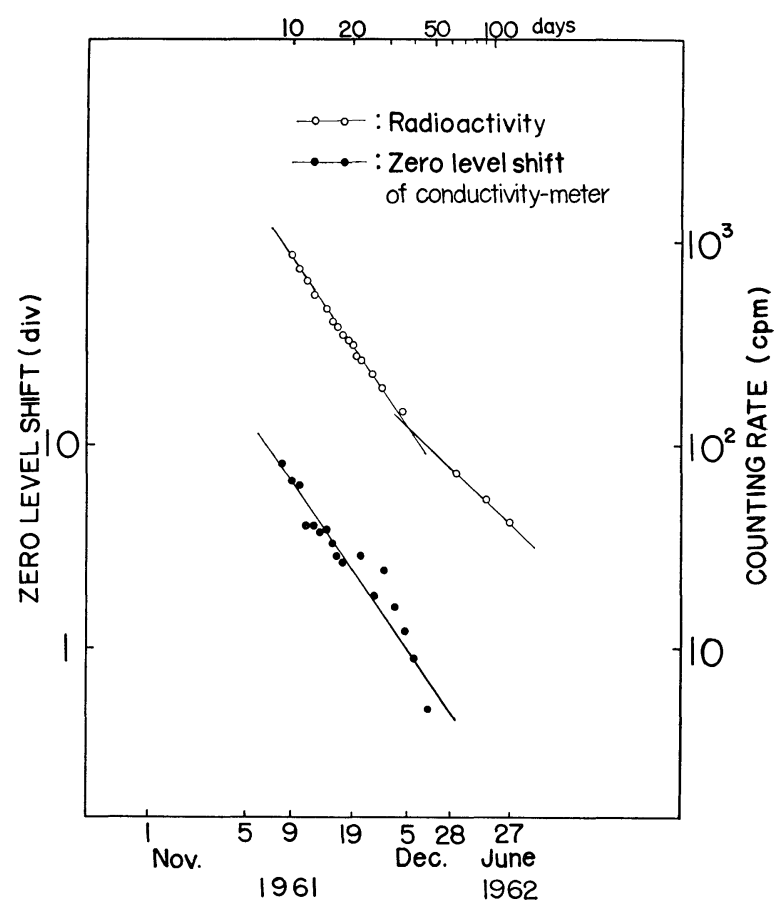

Fig. 4 Recovery of zero level shift of the conductivitymeter and decay characteristic of air-borne dust radioactivity. 
the time elapsed after fission. Debris activity decays more rapidly when the debris contain much the induced radionuclide, ${ }^{239} \mathrm{~Np}$, whose half life is about 2.3 days. This nuclide is produced by the following reaction,

$$
{ }^{238} \mathrm{U}\left(\mathrm{n}_{\gamma}\right){ }^{239} \mathrm{U}, \quad{ }^{239} \mathrm{U} \underset{\beta}{\longrightarrow}{ }^{239} \mathrm{~Np} .
$$

In the present case, debris activity decayed roughly after the equation, $A=A_{0} t^{-1.4}$. The fact that the gradient of the recovery curve of the zero level shift is very similar to that of the decay curve, suggests that the zero level shift was caused by the increase in ionization inside the chamber due to radiations from radioactive dusts deposited on the chamber wall. Such a kind of zero level shift has never been observed since then. Exceedingly much dry fallout seemed to have deposited on the ground on November 7, 1961.

\section{Discussions}

1. Ionization of air by beta radiations from nuclear debris.

Various kind of radionuclides are produced by nuclear fission, and the composition of nuclear debris varies with time, but total activity decreases exponentially as mentioned above. The gamma ray spectrum of the dust sample collected on November 8, 1961 is shown in Fig. 5, in which the photopeaks due to young fission products are revealed. The radionuclides listed below are considered to be dominant ten days after explosion (Hunter and Ballou, 1951; Dhelepov and Peker, 1961).

$$
\begin{aligned}
& { }^{140} \mathrm{La},{ }^{140} \mathrm{Ba},{ }^{143} \mathrm{Pr},{ }^{131} \mathrm{I},{ }^{132} \mathrm{I},{ }^{99} \mathrm{Mo},{ }^{141} \mathrm{Ce} \text {, } \\
& { }^{132} \mathrm{Te},{ }^{147} \mathrm{Nd},{ }^{95} \mathrm{Zr},{ }^{95} \mathrm{Nb},{ }^{91} \mathrm{Y},{ }^{89} \mathrm{Sr},{ }^{103} \mathrm{Ru} .
\end{aligned}
$$

The composition rate of ${ }^{239} \mathrm{~Np}$ is estimated to have been about $30 \% 10$ days after the explosion, from the decay curve shown in Fig. 4. Average beta ray energy of the nuclear debris is calculated to be about $0.3 \mathrm{MeV}$. About $33.2 \mathrm{eV}$ of energy is consumed at one ion pair pro-

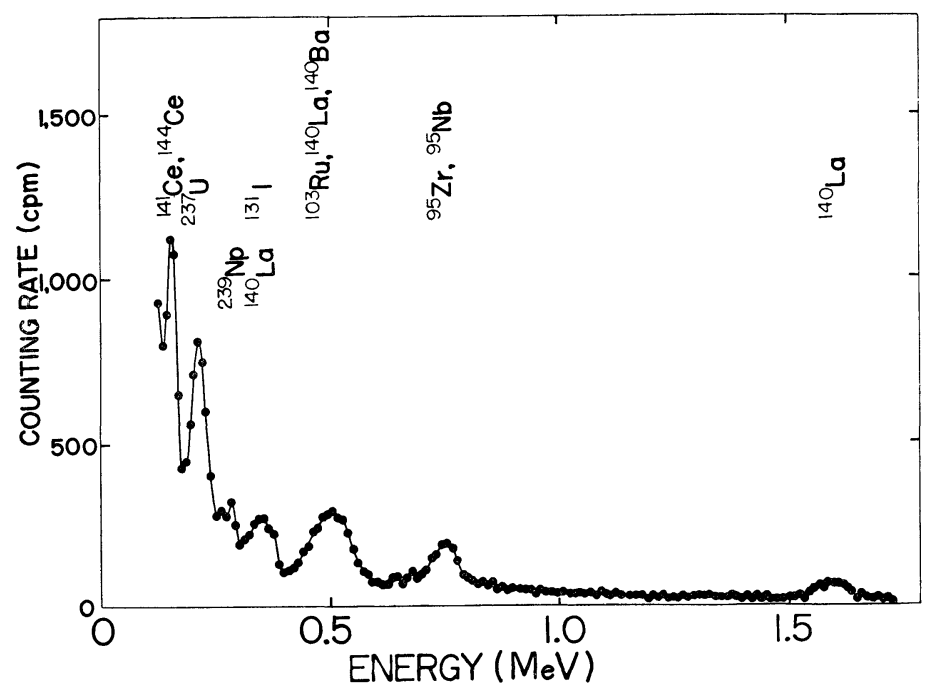

Fig. 5 Gamma ray spectrum of radioactive air-borne dusts collected on November 8, 1961, measured on November 15, 1961. 
duction. And so, about $9 \times 10^{3}$ ion pairs are produced at one $0.3 \mathrm{MeV}$ beta ray emission. One disintegration per second of radioactivity is defined to be $27 \mu \mu \mathrm{Ci}$.

2. Ionization of air by radioactive air-borne dusts.

In the air whose fallout concentration is $120 \mu \mu \mathrm{Ci} / \mathrm{m}^{3}$, ion pairs are produced at the rate of 0.04 ion pairs $/ \mathrm{cm}^{3} \cdot \mathrm{sec}$. Average rate of ionization by natural radiations, such as cosmic radiations, terrestrial radiations and radiations from radon, thoron and their decay products in the air, is about 10 ion pairs $/ \mathrm{cm}^{3} \cdot \mathrm{sec}$. (Hess and Vancour, 1950; Hess and O'Donnell, 1951). Even when fallout concentration in the air reaches some hundred $\mu \mu \mathrm{Ci} / \mathrm{m}^{3}$, the fallout suspended in the air is therefore thought to contribute little to the increase in ionization.

The atmospheric conductivity kept higher value on November 11, 1961 though the fallout concentration had decreased already to a normal low value as shown in Fig. 1. On the contrary as shown in Fig. 3, conductivity varied little on August 10, 1962 when the fallout concentration increased up to $76 \mu \mu \mathrm{Ci} / \mathrm{m}^{3}$. The deposition of radioactive fallout was considerably large during November, 1961 but a little during August, 1962, as shown in the Table 1. These results of observation agree with the above statement.

3. Ionization of the air by fallout accumulated on the ground surface.

The amount of fallout, which was accumulated per $1 \mathrm{~m}^{2}$ of the ground surface every one month through both rainout and dry fallout, was measured by use of a basin and the results are summarized in Table 1. The total fallout deposition increased since a series of nuclear test explosion was set out at the beginning of September 1961. The total fallout activity increased abruptly in November 1961 up to $69.2 \mathrm{~m} \mu \mathrm{Ci} / \mathrm{m}^{2}$, which was measured on December 5, 1961.

Table 1 Fallout deposition accumulated per $1 \mathrm{~m}^{2}$ of the ground surface. $\left(\mathrm{m} \mu \mathrm{Ci} / \mathrm{m}^{2}\right)$

\begin{tabular}{c|r|r|r}
\hline Month & 1960 & 1961 & 1962 \\
\hline Jan. & 1.3 & 0.7 & 33.3 \\
Feb. & 10.4 & 0.7 & 22.6 \\
Mar. & - & 2.0 & 38.6 \\
Apr. & 2.9 & 0.5 & 134.6 \\
May & 3.4 & 1.6 & 137.0 \\
June & 10.0 & 0.8 & 38.2 \\
July & 1.9 & 0.2 & 14.7 \\
Aug. & 1.7 & 0 & 1.7 \\
Sept. & 0.8 & 0.5 & 17.4 \\
Oct. & 1.2 & 27.6 & 14.4 \\
Nov. & 13.0 & 69.2 & 66.4 \\
Dec. & 2.4 & 28.2 & 49.8 \\
\hline
\end{tabular}

On the other hand, rainout activity per $1 \mathrm{~m}^{2}$ of the ground surface was also measured at each rainfall. The activities on December 5, 1961 of the rainouts which were sampled during November are shown in the second column of Table 2. The sum of the figures in the second column is $26.6 \mathrm{~m} \mu \mathrm{Ci} / \mathrm{m}^{2}$. The total fallout activity of $69.2 \mathrm{~m} \mu \mathrm{Ci} / \mathrm{m}^{2}$ was consisted of 
Table 2 Rainout activities during November 1961.

\begin{tabular}{c|c|c}
\hline Date of rainfall & $\begin{array}{c}\text { Radioactivity on } \\
\text { December 5, 1961 } \\
\left(\mathrm{m} \mu \mathrm{Ci} / \mathrm{m}^{2}\right)\end{array}$ & $\begin{array}{c}\text { Rainfall } \\
(\mathrm{mm})\end{array}$ \\
\hline Nov. 3-4, '61 & 0.51 & 12.5 \\
9, & 0.16 & 0.5 \\
$11-12$, & 0.08 & 0.3 \\
13, & 0.14 & 0.7 \\
$17-18$, & 14.10 & 37.6 \\
$20-22$, & 4.52 & 17.6 \\
23, & 1.68 & 2.0 \\
28, & 5.42 & 2.6 \\
\hline sum & 26.61 & 73.3 \\
\hline
\end{tabular}

Table 3 Comparison of total fallout with rainout. $\left(\mathrm{m} \mu \mathrm{Ci} / \mathrm{m}^{2}\right)$

\begin{tabular}{|c|c|c|c|c|c|c|c|c|c|}
\hline Date & $\begin{array}{l}1961 \\
\text { Jan. }\end{array}$ & Feb. & Mar. & Apr. & May & June & July & Aug. & Sept. \\
\hline Total fallout & 0.7 & 0.7 & 2.0 & 0.5 & 1.6 & 0.8 & 0.2 & 0 & 0.5 \\
\hline Rainout & 0.8 & 0.6 & 1.9 & 1.4 & 1.7 & 1.4 & 2.4 & 0.1 & 1.2 \\
\hline Date & Oct. & Nov. & Dec. & $\begin{array}{l}1962 \\
\text { Jan }\end{array}$ & Feb. & Mar. & Apr. & May & June \\
\hline Tatal fallout & 27.6 & 69.2 & 28.2 & 33.3 & 22.6 & 38.4 & 134.6 & 137.0 & 38.2 \\
\hline Rainout & 26.5 & 26.6 & 35.3 & 34.3 & 33.1 & 41.2 & 113.6 & 106.1 & 38.4 \\
\hline
\end{tabular}

rainout component of $26.6 \mathrm{~m} \mu \mathrm{Ci} / \mathrm{m}^{2}$, and dry fallout component of $42.6 \mathrm{~m} \mu \mathrm{Ci} / \mathrm{m}^{2}$.

It is generally considered that more than $90 \%$ of fallout deposits as dry fallout. In Table 3 , are shown the comparison of the total fallout with the sum of the rainout during every one month. Rainout activity was measured by a low background $2 \pi$ gas flow counter which is sensitive to soft beta rays, while the total fallout activity was measured by a G.M. counter. So, there may be some disagreements between the results of the two measurements, but in Table 3 are shown that almost all of the fallout accumulated on the ground surface was due to rainout except in the month soon after the nuclear test explosion, namely, November 1961.

Abnormally much dry fallout must have deposited during November 1961, in consideration of the fact that the chamber wall was contaminated by radioactive dusts. It is assumed that almost all of the dry fallout during November deposited on 7 th and 8th, because the concentration of fallout in the air kept rather low thereafter. The deposited dry fallout activity was estimated to be about $250 \mathrm{~m} \mu \mathrm{Ci} / \mathrm{m}^{2}$ as the value on 9 th, considering the decay characteristic of air-borne dusts as shown in Fig. 4.

The rate of ion pair production within $1 \mathrm{~m}$ above the ground surface was calculated to be about 42 ion pairs $/ \mathrm{cm}^{3} \cdot \mathrm{sec}$. under the assumption that the activity distributed uniformly on the ground surface. This rate of ion pair production is about fourfold of the natural ion pair production rate. It seems possible that the conductivity may be increased twofold when 
the ion pair production rate in the lowest atmosphere increases fivefold, as it will be discussed in section 4.

Much fallout deposited during April and May 1962 as shown in Table 1, but the average atmospheric electrical conductivity in these months did not increase remarkably as shown in Table 4. This may be explained in the following way. The radioactive dry fallout deposits very thinly over the ground surface and therefore radiations from it is absorbed rather little by surface material. The total fallout during these months were mostly consisted of rainout as shown in Table 3. In the case of April and May 1962, radioactive rainout infiltrated into soil and therefore especially soft beta rays from it was considerably absorbed by surface material.

Table 4 Average electrical conductivity of lower atmosphere. $\left(\times 10^{-15} \mathrm{mho} / \mathrm{m}\right)$

\begin{tabular}{c|c|c|c}
\hline Month & 1960 & 1961 & 1962 \\
\hline Apr. & 14.0 & 10.8 & 13.4 \\
May & 15.0 & 10.1 & 12.1 \\
\hline
\end{tabular}

4. Consideration on ion equilibrium condition.

The exact ralation between ion pair production and conductivity is not known. However, we can make an estimate of the relation by consideration of simple expression for ion equilibrium condition;

$$
q-\alpha n^{2}-\beta n N \doteqdot 0
$$

where $q$ is the rate of ion pair production, $\alpha$ is the recombination coefficient for small ions, $n$ is the concentration of small ions, $\beta$ is the attachment coefficient between small ions and aerosol particles and $N$ is the concentration of aerosols. The conductivity is assumed to be proportional to the concentration of small ions; $\lambda=2 n e k$, where $\lambda$ is the conductivity, $e$ is the electronic charge and $k$ is the average ionic mobility of small ions. Harris assumed, in the case of his study, that the conduction will not increase faster than the ionization, and that the concentration of small ions would be much higher than the aerosol concentration in the lowest atmosphere because the value of $q$ was very large. Then the third term of the equation (1) is ignored and the equation is simplified as,

$$
q-\alpha n^{2} \fallingdotseq 0 \text {. }
$$

The equation (2) means that that small ion concentration is roughly proportional to the square root of the ion pair production.

In the present study, the observing station is located at the north-east side of Kyoto City which has the population of about one million without heavy industry. The atmospheric conditions in Kyoto are not considered similar to those in Tucson. If the equation (2), however, is applied to the present case in which the ion pair production rate increased fivefold, small ion concentration is calculated to increase more than twofold. This agrees roughly to the results of the observation in the present investigation in which the conductivity increased in the period from November 8 to 11, 1961 twice as high as the normal value. 


\section{Conclusion}

The atmospheric electrical conductivity was observed to be increased temporarily in Kyoto soon after the very large scale nuclear test explosion of 50 Mega ton class carried out on October 30, 1961. It was found reasonable to relate the increase in conductivity with the increase in dry fallout accumulation on the ground surface, not with the increase in concentration of radioactive dusts in the air.

It is, however, obvious that the examination of data in other station is highly desirable in order to examine whether the effects are world-wide or not and to examine quantitative relation between dry fallout deposition and atmospheric electrical conductivity increase.

The author wishes to express his sincere thanks to Dr. Yuichi Tamura, the professor of Kyoto University, for his kind guidance and encouragement throughout the work. His thanks are also due to Dr. Tetsuo Mamuro, the chief of the department of Health Physics and Instrumentation of the Radiation Centre of Osaka Prefecture, for his guidance in the measurement of radioactivity, and to Dr. Toshio Ogawa, the lecturer of Kyoto University, for lending me the records of atmospheric electricity and for the useful suggestions for the work.

\section{References}

Chalmers, J.A., Atmospheric Electricity, Pergamon Press, London (1957).

Cotton, E.S., Diurnal variation in natural atmospheric radioactivity, J. Atmos. Terr. Phys., 7, 90 (1955). Dzhelepov, B.S., and L.K. Peker, Decay Schemes of Radioactive Nuclei, Pergamon Press, London (1961).

Harris, D. Lee, Effects of radioactive debris from nuclear explosions on the electrical conductivity of the lower atmosphere, J. Geophys. Res., 60, 43 (1955).

Hess, V.F., and G.A. O'Donnell, On the rate of ion formation at ground at one meter above ground, $J$. Geophys. Res., 56, 557 (1951).

Hess, V.F., and R.P. Vancour, The ionization balance of the atmosphere, J. Atmos. Terr. Phys., 1, 13 (1955).

Hunter, H.F., and N.E. Ballou, Fission products decay rates, Nucleonics, 9, No. 5, C2 (1951).

Kawano, M., and S. Nakatani, Some properties of natural radioactivity in the atmosphere, Natural Radiation Environment, The University of Chicago Press, 291 (1964).

Kawano, M., and S. Nakatani, The results of routine observations of the ionizations and the natural radioactive dust concentration in the atmosphere in Tokyo, J. Met. Soc. Japan, 36, 135 (1958).

Kondo, G., Recent status of secular variations of atmospheric electric elements and their relation to the nuclear explosions, Mem. Kakioka Magn. Obs., 8, 75 (1957).

Kondo, G. Recent status of secular variation of atmospheric electricity (II), Mem. Kakioka Magn. Obs., 11, 65 (1963).

Mamuro, T., A. Fujita, T. Matsunami, K. Yoshikawa, and T. Azuma, Radioactive air-borne dusts in Japan, Nature, 194, 643 (1962).

Mamuro, T., A. Fujita, T. Matsunami and K., Yoshikawa, Microscopic examination of highly radioactive fallout particles, Nature, 196, 529 (1962).

Mamuro, T., A. Fujita, T. Matsunami, K. Yoshikawa and T. Azuma, Observation of fallout around our laboratory, Ann. Rept. Rad. Cent. Osaka Pref., 2, 1 (1961).

Ogawa, T.," Diurnal variation in atmospheric electricity, J. Geomagn. Geoelect., 11, 165 (1960 a).

Ogawa, T., Types of diurnal variation of air-earth current, J. Geomagn. Geoelect., 12, 1 (1960 b) 
Pierce, E.T., Nuclear explosions and a possible secular variation of the potential gradient in the atmosphere, J. Atmos. Terr. Phys., 11, 70 (1957).

Pierce, E.T., Some calculations on radioactive fallout with especial reference to the secular variation in potential gradient at Eskdalemuir, Scotland, Geofis. pur. e Appl., 42, 145 (1959). 